\title{
Exploration on the Construction of Applied Computer Specialty Curriculum System
}

\author{
Zijiang Zhu*, Junshan Li, Yi Hu \\ South China Business College, Guangdong University of Foreign Studies, Guangzhou, China \\ Email: ${ }^{\star}$ zzjdwh2002@163.com
}

How to cite this paper: Zhu, Z. J., Li, J. S., \& $\mathrm{Hu}, \mathrm{Y}$. (2018). Exploration on the Construction of Applied Computer Specialty Curriculum System. Creative Education, 9, 1697-1705.

https://doi.org/10.4236/ce.2018.911123

Received: August 3, 2018

Accepted: August 28, 2018

Published: August 31, 2018

Copyright $\odot 2018$ by authors and Scientific Research Publishing Inc. This work is licensed under the Creative Commons Attribution International License (CC BY 4.0).

http://creativecommons.org/licenses/by/4.0/

\begin{abstract}
In view of the problems existing in the traditional professional curriculum system at colleges and universities to cultivate applied undergraduate talents in computer software, this paper, following the concept of "demand-oriented, ability as the core, integration of science and engineering as well as theories and application" and on the basis of deep school-enterprise cooperation, integration of industry and teaching, proposes the "four-connection" professional curriculum system to cultivate applied undergraduate software talents: connecting ability cultivation with the demands for software positions, connecting the curriculum contents with software standard, connecting teaching with development, and connecting incubation projects with the industrial market. And this paper also proposes four measures to guarantee the construction of school-enterprise cooperation: the supporting platform, teaching team, teaching resources and quality guarantee system.
\end{abstract}

\section{Keywords}

Applied Talents, Computer Software, Course System, School-Enterprise Cooperation

\section{Introduction}

With the advancement of the "Internet +" strategy, especially the rapid development of emerging information technology industries such as e-commerce and service outsourcing, the demand for computer software talents in society and industry is increasing. According to incomplete statistics of relevant departments, the demand for IT talents will exceed 1 million each year in the future, and the demand for information, software and network management talents accounts for more than $70 \%$. The number and quality of such graduates trained by colleges and universities each year is far from meeting the needs of the development of the industry. The composite applied talents with both information 
technology and industry knowledge are in short supply (Wang et al., 2018). There is still a big gap between the software talents and the enterprise needs cultivated by the traditional college-oriented professional curriculum system, the single curriculum teaching model and the assessment evaluation mechanism. Ordinary companies have to spend 6 to 12 months and a large amount of cost on pre-employment training for graduates (Yao et al., 2018). How to build a computer software professional course teaching system oriented to the ability needs is a key issue in the application software talent training.

In recent years, some college computer software educators have explored this problem (Jiang, 2017). However, how to construct an application-based undergraduate computer software talent training professional curriculum system under the new situation has not been very successful (Jiang, 2017). Based on deep school-enterprise cooperation and the integration of industry and teaching, this paper proposes a "four-connection" professional curriculum system as well as four measures to guarantee the reform and implementation of the curriculum system.

\section{Analysis of the Status Quo of Professional Curriculum System of Applied Computer Software}

With the continuous improvement of the understanding of application-oriented transformation in society and colleges, local and applied colleges are more and more clear about the orientation of applied talents (Ye et al., 2013). Applied talent development requires an applied curriculum system (Shen et al., 2017). At present, many colleges and universities' software professional curriculum system cannot support the training objectives, and there are the following problems and deficiencies.

\subsection{The Orientation of the Professional Curriculum System Is out of Line with the Demand for Industrial Capabilities}

The ability of design and development of computer software talents in traditional colleges and universities, and the ability to innovate and innovate are generally insufficient, and they are not well qualified for the software positions in the emerging information technology industry (Jiang, 2017). The curriculum teaching system cannot support the core competence training required for software posts. In the orientation of the curriculum system, the discipline and theoretical foundation are overemphasized, and the ability needs are neglected. In the curriculum teaching mode, the students are interned in traditional classrooms and laboratories, ignoring the combination with related industries and enterprises. In the course teaching arrangement, the proportion of theoretical courses is too high, and the proportion of practical courses is seriously insufficient.

\subsection{The Content of Professional Courses Is out of Line with the Actual Production}

The curriculum objective, course content, link arrangement, teaching methods, 
practical path, evaluation mechanism, quality guarantee, etc. of the traditional professional curriculum teaching of computer software are seriously out of line with the ability requirement, technical requirement, organizing form, production process and quality standard of emerging information and technology industry (Yuan, 2014). The course objectives are not consistent with the post-technical segmentation competency requirements; the content of the course is outdated, far away from the current popular software development technology, and not combined with production standards; practical approaches and link arrangements are rarely combined with the actual software development process; The evaluation mechanism only focuses on whether the correct personal practice results are correct or not, rather than whether the productive team project test is passed.

\subsection{Supporting Resource Platform Is out of Line with Professional Teaching Needs}

The professional curriculum system for cultivating applied software talents needs to be supported by a good school-enterprise cooperation platform. It is necessary to have a good school-enterprise cooperation operation mechanism, and a school-enterprise cooperation "double-type" teaching faculty is required. There are teaching resources that interface with software production (Wang et al., 2015). At present, the school-enterprise cooperation of most colleges and universities only stays at the off-campus practice base, focusing only on sending students to the company for internships. There is no mechanism for establishing in-depth cooperative courses with enterprises, and no teachers and teaching resources are introduced. This cannot meet the deep needs of teaching; school-enterprise cooperation still stays in the shallow internship cooperation.

\section{Construction of Professional Applied Computer Software Course System}

\subsection{The Construction Concept of the Professional Curriculum System}

Aiming at the industrial demands and problems existing in the traditional computer software course system, this paper proposes the concept to establish the "demand-oriented, ability as the core, integration of science and engineering as well as theories and practice" professional applied computer software course system. Demand orientation is based on the actual needs of industry for computer software talents, taking into account the graduates' post-adaptability and future career development potential, and the top-level design of the curriculum system; The core of competence, that is, the construction of the curriculum system highlights the cultivation of the various capabilities that the industry and enterprises actually need; the integration of rationality, that is, the overall design theory course and practical curriculum, integrates the theoretical curriculum with the practical curriculum; the integration of engineering and learning refers 
to the design and construction of a curriculum system jointly with the industry and enterprises $(\mathrm{Gu}, 2015)$. The actual development standards, organizational forms and popular technologies of the computer software industry are introduced into the curriculum system, and schools and enterprises jointly implement curriculum teaching.

\subsection{Construction of "Four Connection" Professional Curriculum System for Ability Needs}

1) Connection of ability cultivation with the software post demands, and comprehensive innovation of professional curriculum teaching system.

After extensive research and in-depth analysis, it is combed that the application computer software talents should have three core competencies: "software development capability, business process analysis capability, communication and project management capability". Based on the analysis of the three abilities, design a new professional curriculum system. Three competency courses are built according to the needs of the three core competencies: business process analysis, software development, communication and project management. Determine the connection between the courses in the course group, the series of knowledge points in the course, and set up the practice links such as in-class experiments, independent project training, and enterprise comprehensive internship. From the professional basic knowledge courses in the first and second academic years, the comprehensive application courses in the third year to the professional qualification courses in the industry-related positions in the fourth year, construct a progressively-trained curriculum system. In terms of course credits, the practice hours and credits are greatly improved. Independently set up practical courses plus credits such as graduation internships account for more than $40 \%$ of the total credits, and the main core professional courses take more than $45 \%$ of the total class hours.

2) The content of the course is connected with the software standards, and the method of connotation of the reform of the professional curriculum is deepened.

Starting from the actual position of the computer software industry, according to the requirements of the National Standards for Computer Programmers and the industry standards for service outsourcing software development, the skills and quality requirements and technical standards required for relevant positions are refined and become the teaching standards of the curriculum. Through the three stages of teaching, training and practice of "knowing standards" and "getting familiar with standards" to "using standards", students can consciously follow the technical standards and work requirements after graduation (Huang \& Zhang, 2017).

In the teaching, according to the technical needs of typical software posts combined with the subdivision ability goals of each course, the teaching content, teaching methods, organizational forms, evaluation mechanisms, etc. have been comprehensively reformed. Carry out in-depth analysis of and refine Java/.Net 
development engineers, UI design, Web front-end development engineers, test engineers and other job technical and capability requirements, and integrate these contents into relevant courses by optimizing course materials and practical cases. Integrate professional literacy training into daily teaching and practice, emphasizing basic professional norms such as coding standards and programming habits (Luo et al., 2017).

3) Connect the teaching process with development, emphasizing on cultivating students' post competency.

Combine the professional courses, aim at the subdivision ability of the post needs, and reconstruct the theoretical teaching and practical teaching process. In terms of professional practical teaching, reconstruct the practical teaching system consisting of eight links: professional cognitive internship, professional in-class practice, independent practice course, innovation and entrepreneurship practice, comprehensive project training, holiday post practice, professional graduation internship and job trial. Through the integration of theories and practice, the exchange between on-campus practice and out-campus practice, integration of learning and production, implement the gradual comprehensive practical ability cultivation from "primary to advanced, from simple to comprehensive, from practice to post".

Relying on the off-campus practice base alliance, part or all of the practice of 8 major professional courses such as "Object-Oriented Programming Course Design" will be placed in the enterprise, so that the student's learning process directly connects with the software enterprise production process. The "project development example" takes the software enterprise real development project as the case project, from contract signing, project start-up, design and development to testing and acceptance, the whole process simulation simulates the actual operation in the enterprise, and seamlessly connects the actual development process of software development.

4) The incubation project is connected with the industrial market, and efforts are made to enhance students' ability to innovate and start a business.

Relying on the base association, carry out innovation and entrepreneurship education by holding innovation and entrepreneurship guidance report, salon forums and establishing innovation and entrepreneurship courses, etc. Guide students to innovate and start businesses by setting up an innovative and entrepreneurial team and setting up student innovation R\&D funding projects; promote students' innovation and entrepreneurship by setting up a business incubator project, set up an innovative entrepreneurial studio, and support student registration companies; promote students' innovation and entrepreneurship by setting up a business incubator project, setting up an innovative entrepreneurial studio, and supporting student registration companies; relying on the "Software R\&D Center" and the teacher studio of the industry, academia and research institutes, through the "passing the band" mechanism, students are encouraged to participate in teacher research and enhance students' ability to innovate and 
start their own businesses.

In order to make teaching projects more in line with the development direction of emerging information industry software, docking software industry market. The development projects that are of concern to the base-association enterprises and have good entrepreneurial prospects are selected as innovation and entrepreneurship funding and incubation projects. The company also puts the development, design and testing of some practical projects directly in the school, allowing students to participate in the form of project team research and development and practice.

\section{Measures to Guarantee the Construction of Professional Curriculum System}

1) Construct the school-enterprise cooperation curriculum system supporting platform integrating the mechanism.

To support the cultivation of three core abilities: the software development ability, business process analysis ability, communication and project management ability, on the basis of comprehensively collating the experiment and practice platforms needed by the professional course system and relying on the provincial-level college students' practical education base-Guangzhou Xinbao Software Co., Ltd. Base, this paper comprehensively integrates and improves the professional labs and out-campus practice base and establishes the platform to support the teaching of computer software professional course system with the school-enterprise integration.

In order to better obtain the support from the government, the industry and enterprises, an on-campus computer software talent cultivation guidance committee and practical teaching guidance committed composed of directors, experts and schools, professional leaders and government of government department, provincial computer software industrial association, provincial service and trade association, and computer software enterprises.

In accordance with the principle of "process co-management, mutual benefit and win-win cooperation", we will build a community of talent cultivation and practice teaching-computer software talent training alliance and practice base alliance. With a new and closely integrated school-enterprise cooperation mechanism of "supply and demand docking, resource sharing, benefit sharing, and win-win benefits", talent training will be implemented in schools and enterprises.

2) Co-construct the school-enterprise integration teaching team relying on the "Industry-Learning-Research Collaborative Education Platform".

Relying on the Ministry of Education's “Industry-learning-research collaborative education" project, establish a multidisciplinary and school-enterprise teaching team, and jointly establish a course system and jointly implement teaching. Enterprise engineers participate in the whole process of teaching project and curriculum design, organization, implementation and assessment; the school teach- 
ers serve as enterprise project managers, project team members and enterprise trainers, and participate in project $\mathrm{R} \& \mathrm{D}$, business process design and employee training. The team teaching adopts different modes according to different stages. In the teaching links of theoretical teaching and experiment, internship and training, the team teaching, guidance and assessment mode are adopted; In the stage of enterprise internship, graduation internship and employment trial stage, the company assigns positions and real projects, and the division has full authority to guide and evaluate, and the teacher tracks management mode.

3) Develop teaching resources based on actual projects of enterprises.

School and enterprise based on industry technology and capacity needs, based on the real project of the enterprise, decompose the course knowledge points and skill needs. Combined with the characteristics of curriculum learning and practice, establish a "leave-twig-branch" case project system based on the course case resources and comprehensive corporate project. After it is implemented, students' learning interest and comprehensive practical ability are greatly improved.

10 to 20 case resources have been designed for each core course such as "database" and "object-oriented programming", and schools and enterprises jointly implement theoretical and practical teaching. The company provided and jointly produced 10 large-scale real projects of "Nanguo Business School Smart Campus" and "School Management System" for comprehensive project practical courses, including the project plan, demand analysis manual and summary design specification, industry standard documents such as test plans. On the basis of combing knowledge, skills and cases, the school and enterprise cooperate to develop teaching materials and practical instruction books.

4) Schools and enterprises cooperate to jointly new type of teaching quality evaluation and guarantee system.

According to the principle of "college management, process monitoring, and goal management", the course teaching evaluation system and quality assurance mechanism are constructed. The school-integrated teaching team provides a comprehensive evaluation of students' comprehensive skills such as software development, communication coordination, business analysis, project management, and teamwork. Construct the multi-teaching supervision mechanism "schools, enterprises and students", fully construct the teaching process and status. Through the regular lectures, expert evaluation, corporate feedback, teaching supervision, graduate tracking and other means, the teaching process is monitored and fed back in all aspects.

\section{Conclusion}

After the construction of professional curriculum system and teaching practice, students of computer software majors of Nanguo Business School of Guangdong University of Foreign Studies have made great achievements and progress in publishing papers, obtaining national and provincial student topics, software copyrights, and national and provincial competition awards. Most of the gra- 
duates are employed in well-known service outsourcing companies and software development companies. The "five high" application software talents with relatively high employment rate, high professional compliance rate, high salary, high corporate culture integration and high professional development potential have been cultivated, and enterprises, schools, parents and students are satisfied. According to the data survey of recent graduates in the School Employment Office, the employment rate of graduates of computer software in schools is as high as $99 \%$, and more than $85 \%$ of students are employed in software development and service enterprises. The school's computer science and technology majors and digital media technology majors were respectively approved as provincial-level applied talents training demonstration specialty and featured professional projects. Guangzhou Xinbao Software Co., Ltd. practice teaching base was approved as a provincial-level college students' off-campus practice education base.

\section{Acknowledgements}

This work was supported in part by the Teaching Quality and Teaching Reform Project of Guangdong Province in 2015 for the undergraduate education (Guangdong Education Letter 2015 [133]), they are as follows: the Model Demonstration of computer science and technology applied talents training and the South China Business College of Guangdong University of Foreign Studies-Guangzhou Xinbao Software Technology Co., Ltd. Out-of-school Practice Teaching Base for Undergraduates in Guangdong Province, Guangdong Provincial quality Engineering Project (Guangdong Education High letter [2017] 214), Digital Media Technology feature Specialty Construction (NO. 296).

\section{Conflicts of Interest}

The authors declare no conflicts of interest regarding the publication of this paper.

\section{References}

Gu, H. (2015). Discussion on the Training Programs of Application-Oriented Undergraduate Computer Science and Technology Professionals. Vocational and Technical Education, No. 20, 29-31.

Huang, C. R., \& Zhang, J. D. (2017). Exploration of the Computer Application Talents Training Mode with Deep Integration of School and Enterprise. Computer Education, No. 6, 14-16.

Jiang, Z. L. (2017). The Reform of Computer Specialty under the Background of New Engineering Course Construction. China University Teaching, No. 8, 34-39.

Luo, E. T., Huang, L. S., \& Tang, Y. Y. (2017). Exploration on the Applied University "Double Tutor-Double Ability" Type of Teachers and Collaborative Innovation Mechanism. Laboratory Research and Exploration, No. 7, 253-256.

Shen, H. R., Peng, X. Y., \& Wang, Z. J. (2017). Research on Comprehensive Teaching Reform of Computer Science and Technology in Local Undergraduate Colleges. Journal of Kunming University, 39, 124-129. 
Wang, F. L., Liang, H. Y., Mo, D. L., \& Wang, Q. L. (2018). The Innovative Mode of School-to-Enterprise Cooperation of Applied Undergraduate Course in the New Situation. Computer Education, No. 3, 140-142.

Wang, Y. J., Ma, N., \& Niu, X. L. (2015). Cultivation Mode Reform of Practical Talents in Computer Science and Technology. Computer Science in Education, No. 23, 61-65.

Yao, Y. F., Yu, F. H., \& Li, X. L. (2018). The Teaching Reform and Practice of Cultivating the Innovative Ability of Applied Talents in Computer Major under the Concept of Engineering Education. Journal of Changchun Normal University, 37, 113-119.

Ye, S. P., Chen, C. X., \& Hu, F. J. (2013). Reform of Teaching and Practice for Outstanding ITO Engineers. World Transactions on Engineering and Technology Education, 11, 260-266.

https://www.ixueshu.com/document/2e3f8eef65c1d629318947a18e7f9386.html

Yuan, Y. (2014). Reflections on Cultivating Applied Talents in Local Colleges. China Adult Education, No. 7, 30-33. 